\title{
IMPLEMENTASI FIREBASE CLOUD MESSAGING PADA EMERGENCY CALL BERBASIS ANDROID
}

\author{
Etika Kartikadarma \\ Fakultas Ilmu Komputer, Program Studi Teknik Informatika \\ Universitas Dian Nuswantoro \\ Email: etika.kartikadarma@dsn.dinus.ac.id \\ Widi Widayat Yutriatmansyah \\ Fakultas Ilmu Komputer, Program Studi Teknik Informatika \\ Universitas Dian Nuswantoro \\ Email: 111201106163@mhs.dinus.ac.id \\ Erika Devi Udayanti \\ Fakultas Ilmu Komputer, Program Studi Sistem Informasi \\ Universitas Dian Nuswantoro \\ Email: erikadevi@dsn.dinus.ac.id \\ Nisa'ul Hafidhoh \\ Fakultas Ilmu Komputer, Program Studi Teknik Informatika \\ Universitas Dian Nuswantoro \\ Email: nisa@dsn.dinus.ac.id
}

\begin{abstract}
ABSTRAK
Tindak asusila atau kriminalitas merupakan satu dari banyak faktor serius yang dapat mengancam keselematan atau bahkan nyawa seseorang. Tindak kejahatan atau kriminalitas yang dilakukan baik oleh individu maupun kelompok (komplotan) dapat terjadi dimana saja dan kapan saja. Kebutuhan akan rasa aman menjadi suatu kebutuhan yang sangat penting. Kesadaran masyarakat akan kewaspadaan terhadap tindak kejahatan yang bisa terjadi pun meningkat. Perkembangan perangkat teknologi informasi dan komunikasi meningkat dengan pesat. Penelitian ini mengusulkan solusi berbasis teknologi yang dapat diimplementasikan untuk mengatasi situasi darurat korban kejahatan dengan aplikasi Emergency Call berbasis Android. Penerapan Firebasse Cloud Messaging digunakan untuk menjalankan Push Notification pada Android. Dengan pengembangan aplikasi Emergency Call ini diharapkan dapat mengurangi resiko akibat kejahatan yang lebih serius.
\end{abstract}

Kata kunci: kejahatan; firebasse cloud messaging; emergency call; android.

\begin{abstract}
Immorality or crime is one of the many serious factors that can threaten salvation or even a person's life. Crime or criminal acts committed by individuals or groups (conspirators) can occur anywhere and anytime. The need for security is a very important need. Public awareness of the vigilance of crime that can occur can also increase. The development of information and communication technology devices is increasing rapidly. This study proposes a technology-based solution that can be implemented to address crime victims' emergency situations with an Android-based Emergency Call application. The application of Firebasse Cloud Messaging is used to run Push Notification on Android. The development of the Emergency Call application is expected to reduce the risk of more serious crimes.
\end{abstract}

Keywords: crime; firebasse cloud messaging; emergency call; android.

\section{PENDAHULUAN}

Manusia pada dasarnya tidak dapat memperkirakan bahaya yang dapat mengancam keselamatan atau bahkan nyawa seseorang. Bahaya tersebut dapat terjadi dikarenakan beberapa hal, diantaranya disebabkan oleh pencurian, tindak asusila, kecelakaan, kebakaran, atau fenomena alam. Tindak asusila atau kriminalitas merupakan satu dari banyak faktor serius yang dapat mengancam keselematan atau bahkan nyawa seseorang. Menurut Rusnani yang dikutip oleh Soviati, dkk [1] Kriminalitas merupakan segala macam 
bentuk tindakan dan perbuatan yang merugikan secara ekonomis dan psikologis yang melanggar hukum yang berlaku dalam negara Indonesia serta norma-norma sosial dan agama. Dapat diartikan bahwa tindak kriminalitas adalah segala sesuatu perbuatan yang melanggar hukum dan melanggar norma-norma sosial, sehingga masyarakat menentang. Tindak kejahatan atau kriminal yang dilakukan baik oleh individu maupun kelompok (komplotan) dapat terjadi dimana saja dan kapan saja.

Di Indonesia sendiri angka kriminalitas masih menunjukkan jumlah crime rate yang tinggi dari waktu ke waktu meskipun sifatnya fluktuatif. Berbagai tindak kejahatan terjadi mulai dari penganiayaan, perampokan disertai kekerasan, maupun pelecehan seksual. Bahkan kasus perundungan (buliying) pun bisa menjadi kasus kriminal karena seringkali disertai dengan kekerasan. Tercatat dari hasil survey yang dilakukan oleh Badan Pusat Statitik (BPS) yang disajikan dalam Gambar 1, sejak tahun 2013 hingga tahun 2017 masih banyak masyarakat yang menjadi korban kejahatan [2]. Berdasarkan laporan Badan Pusat Statistik yang dihimpun dari Biro Pembinaan dan Operasional Mabes Polri [3], memperlihatkan jumlah korban akibat tindak kejahatan (crime rate) pada tahun 2017 adalah sebanyak 129 dari setiap 100.000 orang. Sedangkan untuk jumlah kejadian tindak kejahatan (crime total) mencapai 336.652 kasus di tahun yang sama.

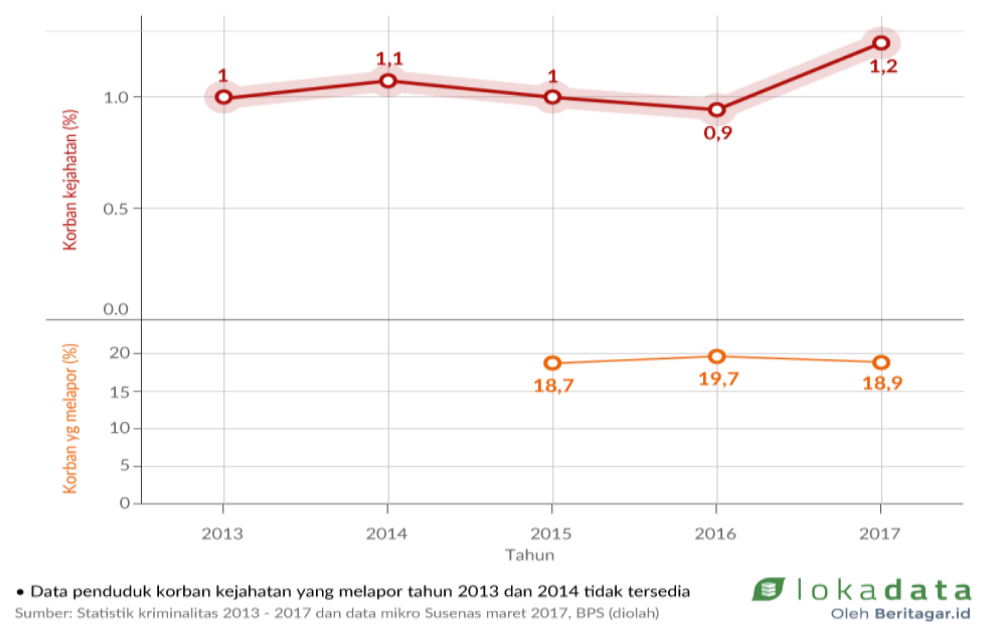

Gambar 1. Pengguna Aktif Smartphone di Indonesia

Dalam kehidupan sosial masarakat, kebutuhan akan rasa aman menjadi suatu kebutuhan yang sangat penting selain dari ketercukupan kebutuhan pokok. Kesadaran masyarakat akan kewaspadaan terhadap tindak kejahatan yang bisa terjadi pun meningkat. Dukungan pemerintah akan rasa aman di mayarakat sangat diperlukan. Setiap individu masyarakat segala usia mulai dari anak-anak sekolah bahkan orang dewasa akan sangat memerlukan pertolongan saat terjadi tindak kejahatan. Akan tetapi hal ini menjadi sulit apalagi kejahatan ini terjadi jauh dari keramaian, jauh dari jangkauan keluarga, maupun jauh dari kepolisian. Tidak jarang para korban kejahatan kesulitan mencari bantuan terdekat dan cepat. Layanan sambungan yang disediakan oleh pihak kepolisian adalah melalui layanan telepon ataupun harus mendatangi kantor kepolisian. Pola konvensional tentu tidak bisa memberikan bantuan cepat bagi korban tindak kejahatan. Solusi terhadap kondisi minimnya pertolongan cepat ini sangat diperlukan ditengah masyarakat.

Di sisi lain, perkembangan perangkat teknologi informasi dan komunikasi meningkat dengan pesat yang salah satunya adalah kemampuan smartphone. Pertumbuhan pengguna smartphone ini juga terus mengalami peningkatan. Dilansir dari laman techniasia [4], emarketer melaporkan bahwa pada tahun 2018 pengguna smartphone di Indonesia mencapai 103 juta pengguna aktif. 


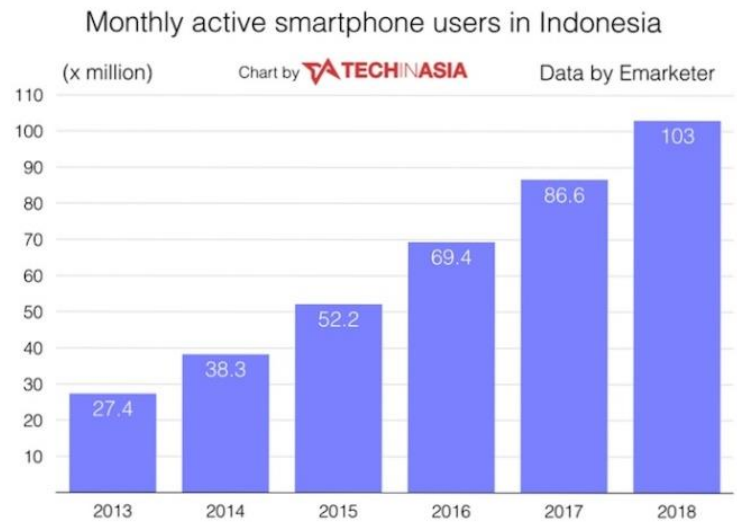

Gambar 2. Pengguna Aktif Smartphone di Indonesia

Tercatat hingga 2019 pengguna ponsel pintar meningkat dan mencapai 92 juta jiwa dari tahun sebelumnya yaitu 83,5 juta jiwa di tahun 2018 . Kemampuan ponsel pintar saat ini yang dapat mendeteksi lokasi device seseorang dapat dimanfaatkan untuk pencarian lokasi terkini.

Purwo Riwayadi, mendeskripsikan teknologi informasi yaitu teknologi yang digunakan untuk mengolah, memproses, mendapatkan, menyusun, menyimpan, hingga memanipulasi data dalam berbagai cara untuk dapat menghasilkan sebuah informasi yang akurat, berkualitas dan tepat waktu [5]. Sehingga informasi tersebut dapat digunakan oleh pihak-pihak terkait dalam pengambilan keputusan. Di era sekarang, hampir segala bidang telah memanfaatkan produk dari teknologi informasi.

Perkembangan teknologi pada zaman digital seperti saat ini dapat sangat membantu dalam kehidupan sehari- hari [6]. Dengan adanya teknologi yang berkembang pesat diharapkan dapat membantu meningkatkan proses penanggulangan jika terjadi hal - hal yang tidak diinginkan seperti halnya tindak kejahatan. Sebuah penelitian pada pengembangan perangkat lunak berbasis android yang dilakukan oleh Mita Septiana Chumairoh dkk., dalam membangun sistem informasi akademik yang dapat diakses melalui mobile device. Aplikasi android ini dibangun dengan HTML5, dan hybrid application, serta memanfaatkan layanan google cloud messaging yang digunakan untuk mentransfer pesan atau notifikasi ke perangkat android [7]. Hal ini ditujukan agar pengguna sistem informasi akademik yaitu mahasiswa lebih mudah dalam mendapatkan informasi dari website Unipdu tanpa harus berkunjung ke website secara langsung. Dalam penelitian lain, dikembangkan prototipe aplikasi pengumuman kelas menggunakan teknologi Firebase Cloud Messaging pada sebuah aplikasi android yang dapat memberikan informasi kegiatan waktu belajar-mengajar pada mahasiswa yang mengambil kelas tersebut berupa notifikasi yang dikirim melalui web server ke client [8].

Penelitian ini mengusulkan solusi bantuan cepat berbasis teknologi yang dapat mengirimkan notifikasi atau pemberitahuan ke pihak- pihak terkait melalui perangkat mobile android. Aplikasi Emergency Call mengirimkan notifikasi dengan mengimplementasikan layanan Firebase Cloud Messaging (FCM). Notifikasi yang dikirimkan akan membagikan posisi lokasi korban sehingga akan lebih memudahkan menuju lokasi tindak kejahatan terjadi. Aplikasi Emergency Call dapat terhubung ke keluarga maupun kantor kepolisian terdekat. Dengan pengembangan aplikasi Emergency Call ini diharapkan dapat mengurangi resiko akibat kejahatan yang lebih serius.

\section{METODOLOGI PENELITIAN}

Dalam penelitian ini, mengimplementasikan pengembangan perangkat lunak dengan metode prototyping [9] dalam pengembangan aplikasi Emergency Call. Proses iteratif ini dapat mengadaptasi apalagi muncul perubahan dalam proses pengembangan (development), sehingga dapat secara simultas diperbaiki melalui komunikasi dan pemahaman kebutuhan sistem antara pengguna dengan pengembang sistem. Gambar 3 menggambarkan tahapan prototyping dalam penelitian yang mengadopsi dari metodologi pengembangan sistem [9]. 


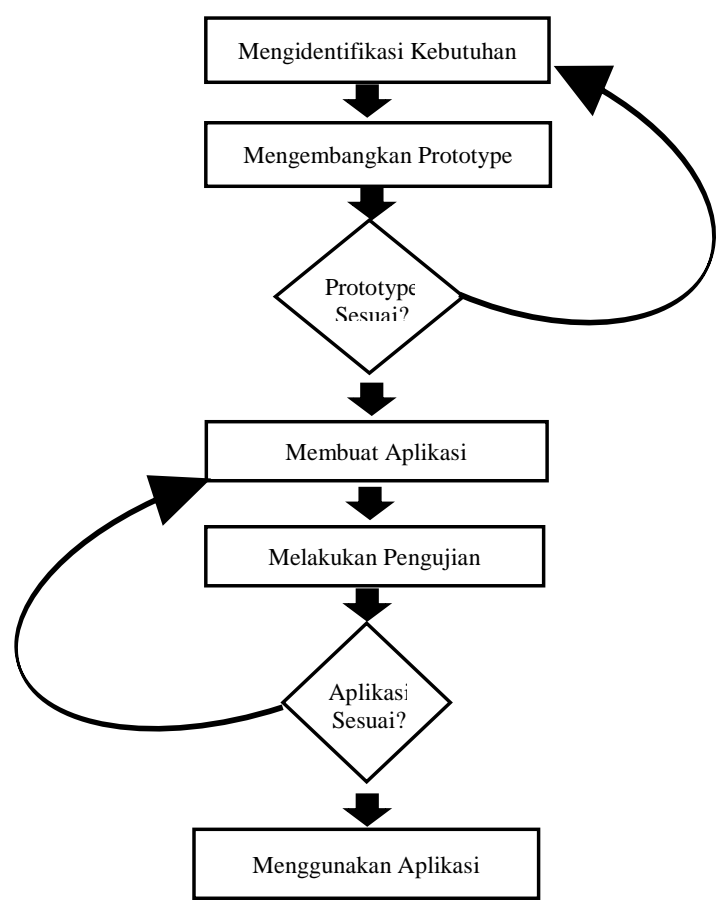

Gambar 3. Metode Prototyping

Tahapan-tahapan dalam membuat prototype adalah :

a) Mengidentifikasi Kebutuhan Pemakai

Pada tahap ini dilakukan identifikasi kebutuhan aplikasi emergency call yang terdiri dari kebutuhan fungsional dan non fungsional sistem. Serta dibuat rancangan arsitektur sistem yang hendak dibangun untuk memudahkan proses pembuatan aplikasi.

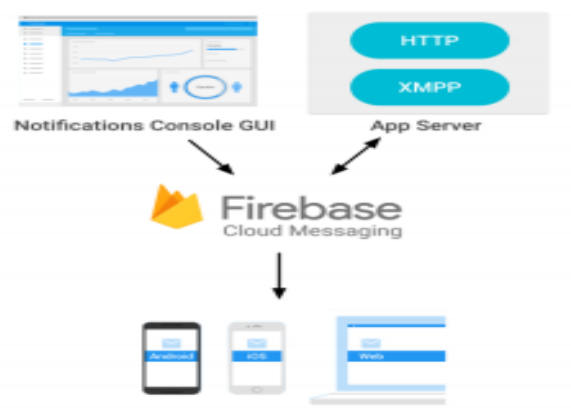

Gambar 4. Arsitektur FCM

b) Mengembangkan Prototype

Pada tahapan ini dilakukan implementasi dari desain sistem sesuai dengan kebutuhan pengguna yaitu dengan melakukan pengkodean ke dalam bahasa pemrograman. Dimana dalam pengembangan layanan notifikasi emergency call menggunakan arsitektur Firebase Cloud Messaging (FCM) sebagaimana dalam Gambar 4 [10]. Hasil dari pengkodean yang dilakukan yaitu prototipe aplikasi emergency call secara keseluruhan dengan menggunakan Android Studio, Visual Studio Code, Firebase Cloud Messaging (FCM), PHP, MYSQL sebagai database engine.

c) Menguji Prototype

Guna memastikan aplikasi dapat berjalan dengan dan tanpa kesalahan maka dilakukan pengujian sistem. Dalam penelitian ini pengujian sistem dilakukan dengan menggunakan metode white box testing. Pengujian dilakukan pada masing- masing modul aplikasi.

d) Memperbaiki Prototype

Untuk setiap perubahan yang muncul dalam proses pembuatan aplikasi, tentu diperlukan perbaikan pada prototipe yang telah dibangun. untuk memastikan bahwa aplikasi sesuai dengan kebutuhan. 


\section{HASIL DAN PEMBAHASAN}

Hasil dari penelitian akan diuraikan mengikuti metodologi pengembangan sistem yang diadopsi. Dimana akan dimulai dari identifikasi kebutuhan sistem baik kebutuhan fungsional dan non fungsional, arsitektur perangkat lunak, pembuatan prototipe, hingga pengujian sistem.

\subsection{Identifikasi kebutuhan}

Identifikasi kebutuhan pemakai digunakan untuk menggambarkan fungsi dan fitur sistem dari perspektif pengguna agar aplikasi sesuai dengan keinginan pengguna. Adapun kebutuhan fungsional aplikasi Emergency Call yang dikembangkan ditunjukkan dalam Data Flow Diagram (DFD) pada Gambar 4 yaitu:
a) Fungsi registrasi.
b) Fungsi login aplikasi.
c) Fungsi pesan darurat.
d) Fungsi Peta dan Rute jarak yang akan ditempuh.

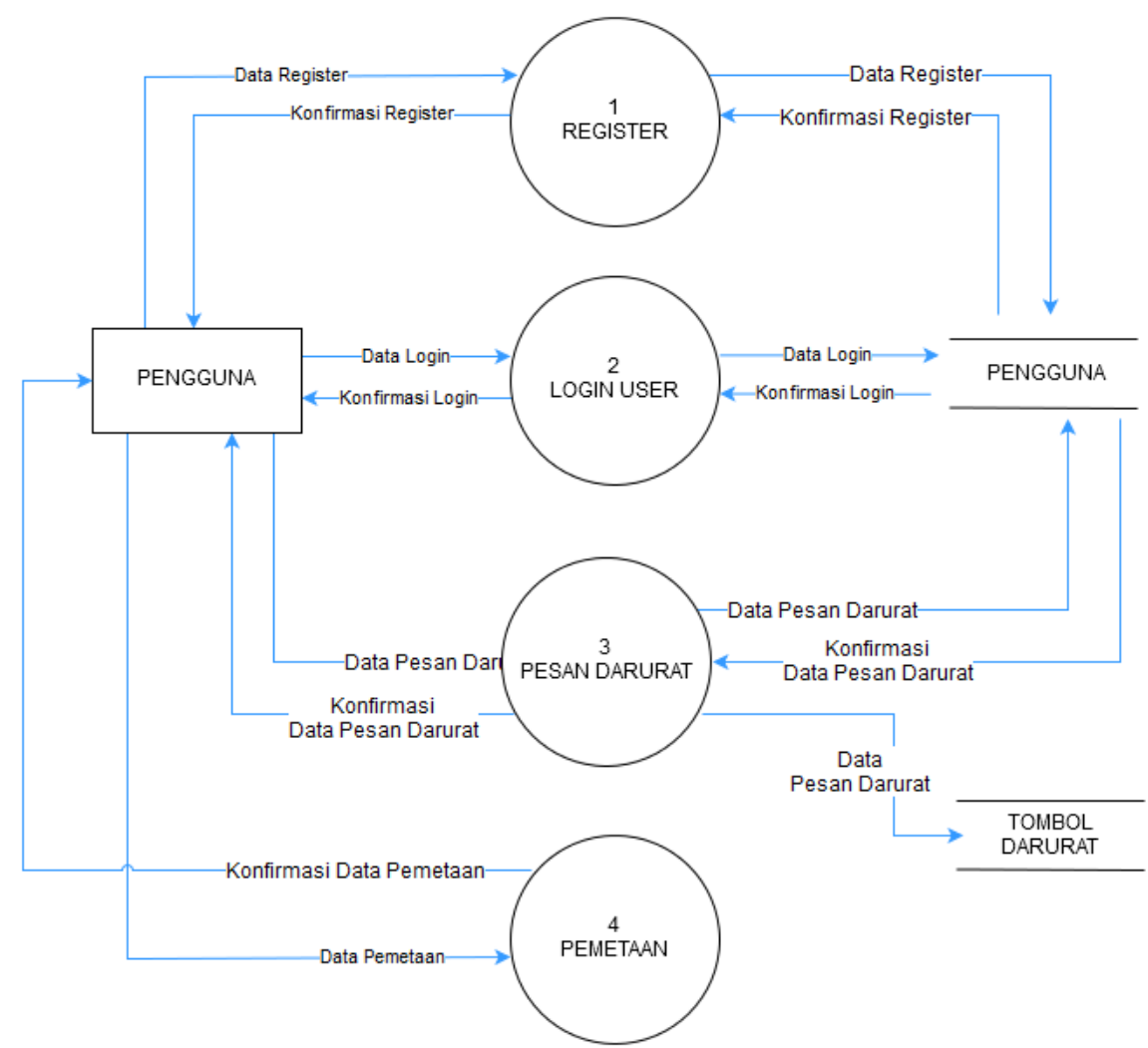

Gambar 4. DFD Aplikasi Emergency Call

Sedangkan untuk kebutuhan non-fungsional pengembangan aplikasi disajikan dalam Tabel 1. Kebutuhan non-fungsional aplikasi dikategorikan dalam 4 kategori.

Tabel 1. Kebutuhan Non Fungsional

\begin{tabular}{cll}
\hline No & \multicolumn{1}{c}{ Kategori } & \multicolumn{1}{c}{ Deskripsi } \\
\hline 1 & Data & Pengguna, Pesan Darurat \\
2 & Platform software & Tool : Android Studio 3.1, Visual Studio Code \\
& pengembangan & DBMS : MySQL 5.0 \\
& & Service : Firebase Cloud Messaging, Google Maps \\
3 & Ukuran file & Aplikasi berkapasitas kurang dari 20MB \\
4 & Storage & Memiliki ruang kosong minimal 30MB \\
5 & Performance & Notifikasi lintas platform \\
\hline
\end{tabular}




\subsection{Arsitektur Sistem}

Arsitektur sistem yang akan dikembangkan ditunjukkan pada Gambar 5. Sistem secara umum terdiri dari 3 elemen proses utama yaitu pendaftaran, proses sinyal darurat, notifikasi darurat. Data akan diproses di dalam server kemudian layanan Firebase Cloud Messaging mengirimkan data tersebut ke Cloud. Setelah data diproses dari Firebase Cloud Messaging selanjutnya akan menjalankan Push Notification dengan mengirimkan data ke pengguna yang dituju. Ponsel pengguna akan mengirim notifikasi ke tujuan penerima kedaruratan. Aplikasi Emergency Call ini dilengkapi dengan Pemetaan yang memanfaatkan layanan Google Maps. Setiap pengguna yang menerima notifikasi dapat melihat posisi, alamat dan jarak tempuh dari korban. Pengguna juga dapat menambahkan teman dan menentukan kepada siapa tombol darurat akan dikirimkan.

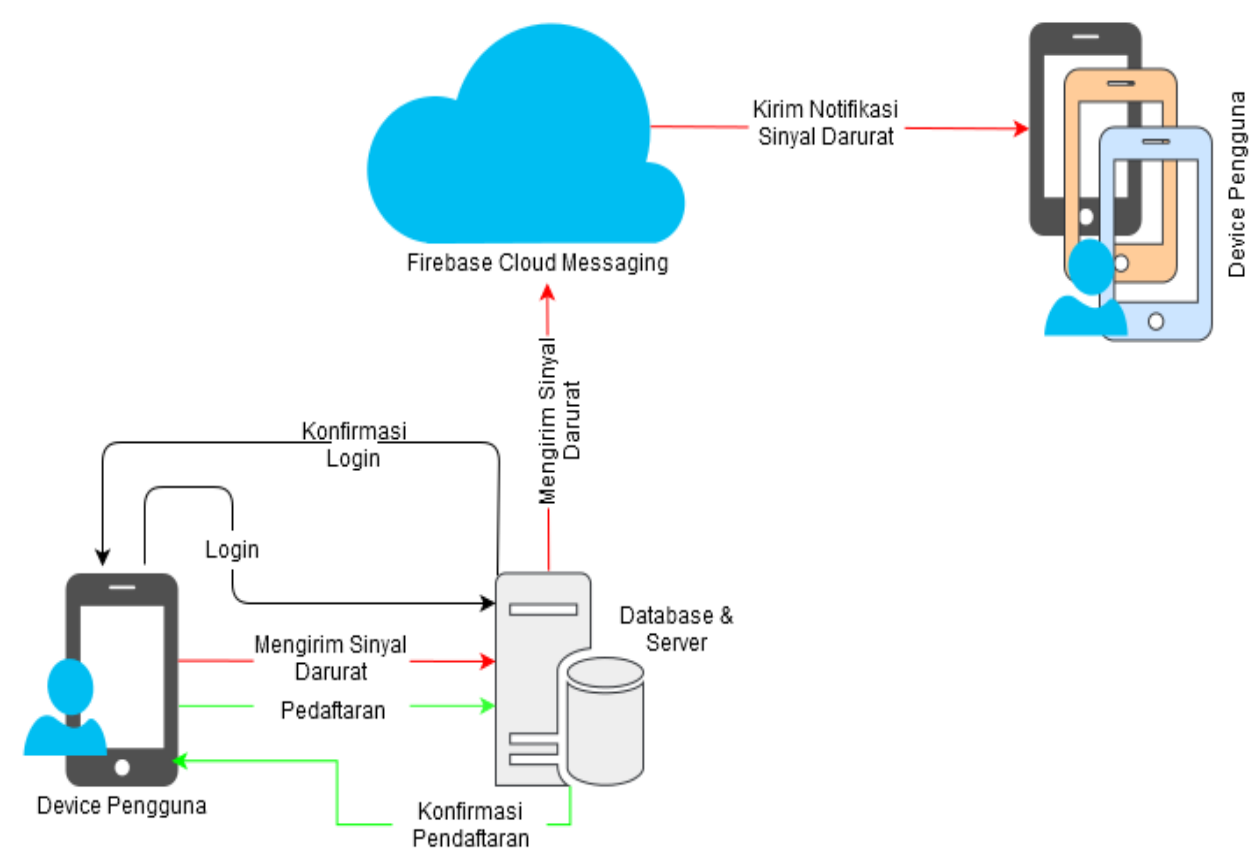

Gambar 5. Arsitektur Sistem

\subsection{Pembuatan Prototype}

Dari identifikasi kebutuhan sistem yang sudah terkumpul selanjutnya diimplementasikan dalam bahasa pemrograman. Firebase Cloud Messaging diimplementasikan dalam tombol darurat. Adapun hasil implementasi yang sudah dibuat adalah prototype aplikasi Emergency Call pada Gambar 6.

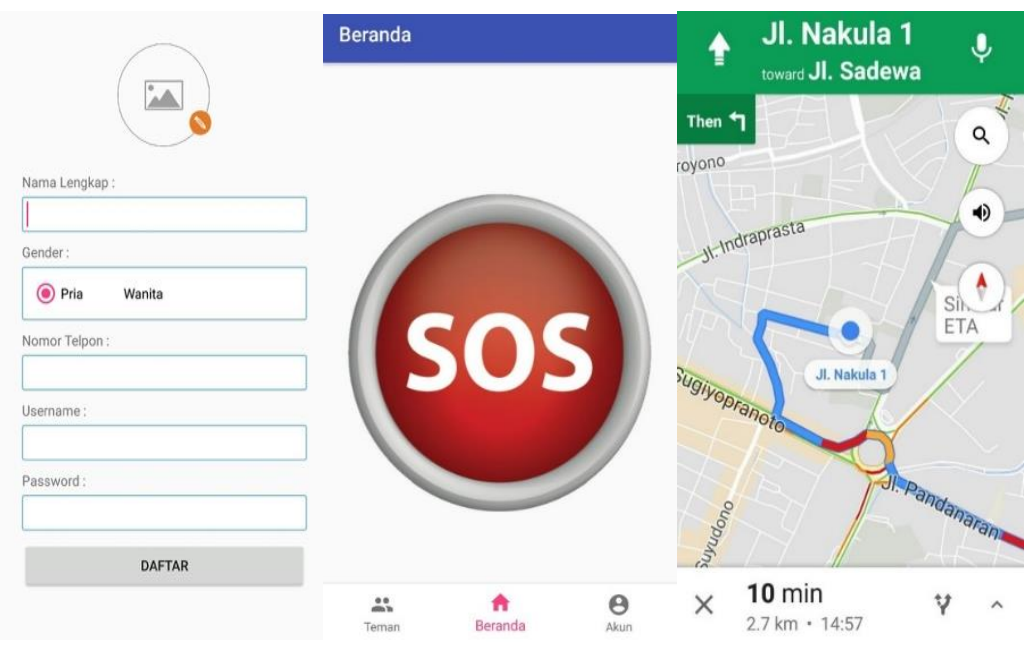

Gambar 6. Antarmuka Prototype Aplikasi Emergency Call 


\subsection{Pengujian Sistem}

Pada pengujian sistem dilakukan dengan metode white box testing dengan memetakan alur program ke dalam suatu bagan alir control (flowgraph) yang selanjutnya dilakukan perhitungan kompleksitas siklometik. Jika jumlah region, Cyclomatic Complexity (CC) dan independent path sama besar maka sistem dinyatakan benar. Akan tetapi, jika sebaliknya maka sistem masih memiliki kesalahan, mungkin dari segi logika maupun dari sisi lainnya. Untuk rumus perhitungan kompleksitas siklometik yaitu:

$V(G)=E-N+2$

dimana diketahui :

$\mathrm{E}=$ Jumlah edge pada flowgraph

$\mathrm{N}=$ Jumlah node pada flowgraph

Salah satu perhitungan kompleksitas siklometik untuk modul tombol darurat adalah:
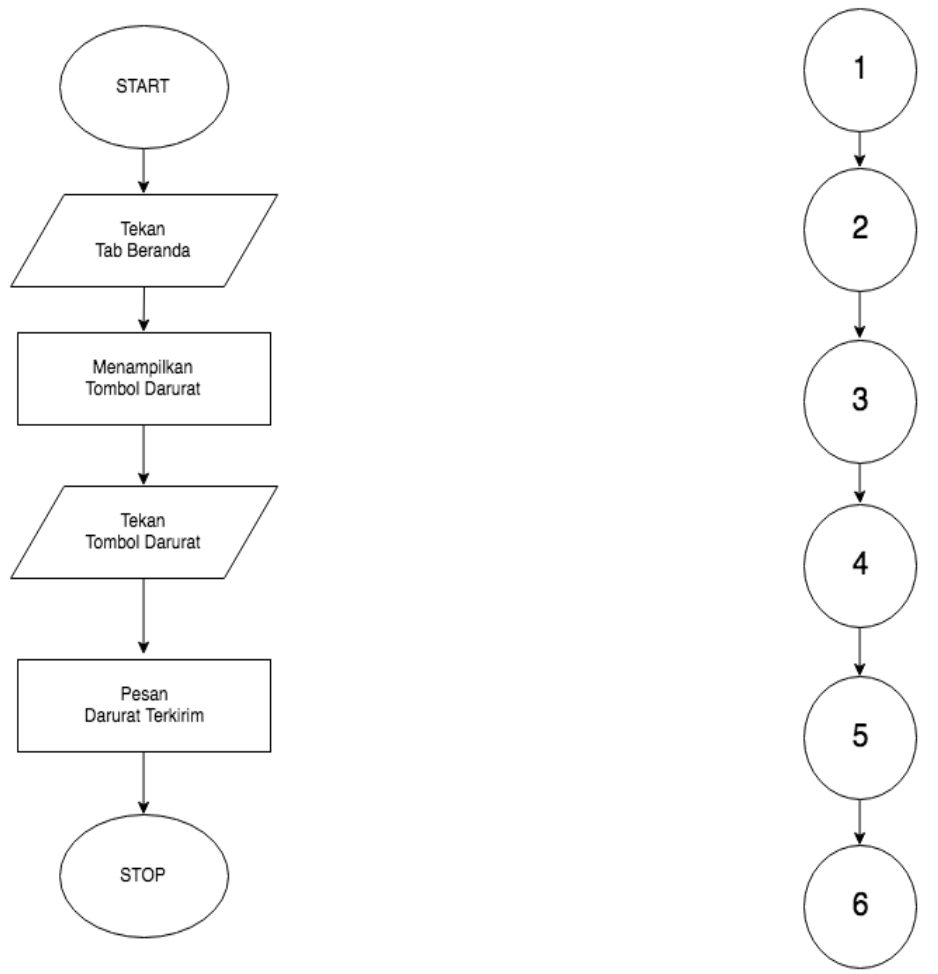

Gambar 7. Flowchat dan Flowgraph Modul Tombol Darurat

Pada flowgraph modul tombol darurat, dapat dihitung cyclomatic complexity sebagai berikut:

$\mathrm{V}(\mathrm{G})=5$ edges -6 nodes +2

$\mathrm{V}(\mathrm{G})=1$

Independent Path :

Path $1: 1-2-3-4-5-6$

Tabel 2 menyajikan rekapitulasi pengujian yang telah dilakukan terhadap enam modul yang telah diuji yaitu modul login, register, tombol darurat, daftar teman, peta rute, dan terakhir modul akun. 
Tabel 2. Rekapitulasi Hasil White Box Testing

\begin{tabular}{|c|c|c|c|c|c|}
\hline \multicolumn{6}{|c|}{ Rekapitulasi Hasil Pengujian Perangkat Lunak } \\
\hline No & Kategori Modul & $V(G)$ & Region & Path & Kondisi \\
\hline 1 & Modul Login & 2 & 2 & 2 & Accepted \\
\hline 2 & Modul Register & 1 & 1 & 1 & Accepted \\
\hline 3 & $\begin{array}{l}\text { Modul Beranda/Tombol } \\
\text { Darurat }\end{array}$ & 1 & 1 & 1 & Accepted \\
\hline 4 & Modul Daftar Teman & 2 & 2 & 2 & Accepted \\
\hline 5 & Modul Peta Rute & 1 & 1 & 1 & Accepted \\
\hline 6 & Modul Akun & 2 & 2 & 2 & Accepted \\
\hline
\end{tabular}

\section{KESIMPULAN}

Dari keseluruhan tahapan proses penelitian yang telah dilakukan dalam pengembangan aplikasi Emergency Call berbasis android, dapat ditarik kesimpulan yaitu bahwa penerapan firebase cloud messaging sebagai pemberitahuan tanda bahaya pada rancang bangun aplikasi Emergency Call berbasis Android berhasil diimplementasikan. Rekapitulasi hasil pengujian dengan metode white box testing menunjukkan aplikasi telah benar dan tidak memiliki kesalahan baik dari segi logika maupun fungsi dan layak untuk diimplementasikan.

\section{SARAN}

Untuk penelitian lebih lanjut, pengembangan aplikasi dapat diarahkan untuk platform lain diluar sistem operasi android, misalnya pada sistem operasi ios. Selain itu juga dikembangkan lagi fungsional aplikasi Emergency Call yang terkoneksi ke pihak-pihak terkait lainnya seperti kepolisian dan rumah sakit. Serta pengembangan fungsional sistem untuk menyunting akun seperti foto profile, nomor telepon, username dan password. Untuk melihat pandangan pengguna, dapat dilakukan analisis tingkat penerimaan pengguna aplikasi Emergency Call yang telah dikembangkan.

\section{DAFTAR PUSTAKA}

[1] B. M. Soviati, F. Fakhruddin, and I. Ilyas, "Pembinaan Anak Rentan Tindak Kriminal melalui Kube pada Anak Binaan PSMP Antasena Magelang," J. Nonform. Educ. Community Empower., vol. 1, no. 2, pp. 128-136, 2018.

[2] A. Adzkia, "Korban kejahatan meningkat, laporan justru menurun," Beritagar.id, 2018. [Online]. Available: https://beritagar.id/artikel/berita/korban-kejahatan-meningkat-laporan-justru-menurun.

[3] Badan Pusat Statistik, "Statistik Kriminal 2018," 2018.

[4] S. Millward, "Indonesia diproyeksi lampaui 100 juta pengguna smartphone di 2018, keempat di dunia," Techinasia, 2014. .

[5] S. Ameliola and H. Dwiyudha Nugraha, "Pemanfaatan Perkembangan Teknologi Informasi Dan Komunikasi Untuk Kemajuan Pendidikan di Indonesia," 2013.

[6] M. M. Rizki Saputra, Ir. Sutanto, "Prototype Panic Button Dengan Notifikasi SMS dan Peta Digital," 2015.

[7] M. S. Chumairoh, "Perancang Bangun Aplikasi Mobile Pada Platform Android Berbasis Html5 Studi Kasus Layanan Informasi Website Unipdu Jombang," Edutic, vol. 1, no. 1, pp. 1-6, 2014.

[8] F. Prayoga, "Perancangan Prototype Aplikasi Pengumuman Kelas Menggunakan Teknologi Firebase Cloud Message Pada Android," Universitas Kristen Satya Wacana, 2008.

[9] I. Sommerville, Software engineering, 9th ed. Pearson, 2009.

[10] M. Ilhami, "Pengenalan Google Firebase Untuk Hybrid Mobile Apps Berbasis Cordova," TI CIDA, vol. 3, no. 1, 2017. 